\title{
Exon 20 YVMA insertion is associated with high incidence of brain metastasis and inferior outcome of chemotherapy in advanced non-small cell lung cancer patients with HER2 kinase domain mutations
}

\author{
Shuo Yang ${ }^{1 \#}$, Yan Wang ${ }^{1 \#}$, Chao Zhao ${ }^{2}$, Xuefei Li $^{2}$, Qian Liu ${ }^{1}$, Shiqi Mao ${ }^{1}$, Yiwei Liu ${ }^{1}$, Xiaofei Yu ${ }^{1}$, \\ Wanying Wang ${ }^{1}$, Qinrun Tian ${ }^{1}$, Yingying Pan $^{1}$, Anwen Xiong ${ }^{1}$, Bin Chen ${ }^{1}$, Guanghui Gao ${ }^{1}$, Wei Li ${ }^{1}$, \\ Yayi He ${ }^{1}$, Fengying $\mathrm{Wu}^{1}$, Xiaoxia Chen ${ }^{1}$, Chunxia Su${ }^{1}$, Shengxiang Ren ${ }^{1}$, Caicun Zhou ${ }^{1}$ \\ ${ }^{1}$ Department of Medical Oncology, Shanghai Pulmonary Hospital and Thoracic Cancer Institute, Tongji University School of Medicine, Shanghai, \\ China; ${ }^{2}$ Department of Lung Cancer and Immunology, Shanghai Pulmonary Hospital, Tongji University School of Medicine, Shanghai, China \\ Contributions: (I) Conception and design: S Ren; (II) Administrative support: X Chen, C Su, S Ren, C Zhou; (III) Provision of study materials or \\ patients: C Zhao, X Li, A Xiong, B Chen, W Li, G Gao, F Wu, Y He; (IV) Collection and assembly of data: S Yang, Y Wang, Q Liu, S Mao, Y \\ Liu, X Yu, W Wang; (V) Data analysis and interpretation: S Yang, Y Wang, Q Liu, S Mao, Y Liu; (VI) Manuscript writing: All authors; (VII) Final \\ approval of manuscript: All authors. \\ \#These authors contributed equally to this work. \\ Correspondence to: Prof. Shengxiang Ren, MD, PhD. Department of Medical Oncology, Shanghai Pulmonary Hospital and Thoracic Cancer Institute, \\ Tongji University School of Medicine, No. 507, Zheng Min Rd, Shanghai, 200433, China. Email: harry_ren@126.com.
}

Background: Chemotherapy remains the standard care for HER2 mutated advanced non-small cell lung cancer (NSCLC) even though several targeted drugs showed promising results in preliminary stages. This study aimed to investigate the association of mutation variants with clinical features and the efficacy of chemotherapy in patients with HER2 mutated advanced NSCLC.

Methods: ARMS-PCR was used to identify HER2 mutation in patients without common oncogenic alterations. Patients with detailed information were further enrolled for analysis of clinical features and efficacy of first line chemotherapy. Survival data was analyzed by Kaplan-Meier method and compared by log-rank test. Brain metastasis incidence was analyzed and compared by Gray's test.

Results: YVMA insertion accounted for the majority $(68.4 \%, 67 / 98)$ of HER2 mutation, and associated with significantly higher incidence of baseline extrathoracic metastasis $(\mathrm{P}=0.009)$, notably brain metastasis $(\mathrm{P}=0.004)$. Among 82 patients those received first line chemotherapy, YVMA insertion remarkably associated with inferior treatment outcomes, namely, a significantly shorter median progression free survival (PFS) and lower objective response rate (ORR) both in total patients (PFS: 5.2 vs. $7.7 \mathrm{~m}, \mathrm{P}=0.038$; ORR: $30.9 \%$ vs. 51.9\%, $\mathrm{P}=0.09$ ) and pemetrexed subgroup (PFS: 5.2 vs. $6.5 \mathrm{~m}, \mathrm{P}=0.022$; ORR: $31.8 \%$ vs. 60.0\%, $\mathrm{P}=0.054$ ). Multivariate analysis further established YVMA insertion as prognostic factor of worse PFS both for total patients ( $\mathrm{HR}=1.578,95 \% \mathrm{CI}, 0.956-2.606)$ and patients received pemetrexed-based chemotherapy (HR $=1.789,95 \%$ CI, 1.013-3.160). In addition, YVMA insertion associated with higher incidence of lifetime brain metastasis $(\mathrm{P}=0.002)$ compared by Gray's test, with estimated 12 -month brain metastasis incidence as $40.2 \%$ compared with $3.6 \%$ in the non-YVMA group.

Conclusions: YVMA insertion is associated with a higher incidence of brain metastasis, and inferior outcomes to chemotherapy than non-YVMA variants in patients with advanced NSCLC and HER2 kinase domain mutations, which emphasized the unmet need of more potent anti-cancer therapies with high bloodbrain barrier (BBB) penetration capacity for patients with YVMA insertion.

Keywords: HER2 mutation; YVMA insertion; brain metastasis; chemotherapy; non-small cell lung cancer (NSCLC) 
Submitted Apr 16, 2020. Accepted for publication Dec 21, 2020.

doi: $10.21037 /$ tlcr-20-559

View this article at: http://dx.doi.org/10.21037/tlcr-20-559

\section{Introduction}

Targeted therapies have dramatically revolutionized treatment paradigm with higher response rates, longer progression-free survival (PFS) and less side effects compared with chemotherapy in advanced non-small cell lung cancer (NSCLC) patients harboring EGFR/ALK/ $R O S 1 / B R A F$ alterations (1-4). Rare mutations, such as $K R A S, R E T$, and MET are also recommended for molecular detection in those patients without common oncogenic mutations with several drugs approved for treatments or in clinical trials (5-8).

HER2 kinase domain mutation has been increasingly acknowledged as a promising therapeutic target in advanced NSCLC with an incidence of $4.8 \%$ in patients without sensitizing EGFR mutations (9-11). Multiple HER2targeted drugs showed promising treatment efficacy (12-16) such as neratinib (17), poziotinib (18) and pyrotinib $(15,19)$ which showed an ORR of $53.3 \%$ and PFS of 6.4 months in HER-mutated NSCLC in our previous report. Antibody drug conjugates (ADC) like T-DM1 $(20,21)$ and DS-8201a $(22,23)$ have also shown great potency in HER2 mutated NSCLC, with T-DM1 having been recommended by the NCCN guideline (5). However, currently, targeted drugs have not yet been approved and chemotherapy remains the current standard of care in this setting $(24,25)$.

Increasing evidences have demonstrated that even within the same oncogenic driver, clinical characteristics and treatment efficacy could be dramatically different. For example, patients with EGFR 19del have longer PFS and survival benefit compared with patients with EGFR L858R substitution (26,27). Different $A L K$ variants and $B R A F$ mutation classes have also been demonstrated to correlate with discrepant treatment outcomes, survival outcomes, and baseline clinical features (28-33). Furthermore, mutation variants also associated with different resistance mechanisms. For example, EGFR $19 \mathrm{del}$ associates with a higher incidence of T790M (34), and the $A L K$ variant 3 with a higher incidence of G1202R (30). In addition, mutation variants also have been demonstrated to be related to different levels of tumor mutation burden (TMB) (35). Same has also been observed in HER2 mutated NSCLC, recently a study demonstrated that patients with different
HER2 mutations showed discrepant responses to afatinib, a pan-HER inhibitor (36). Collectively, these data suggest that identification of mutation variants could guide the proper choice of therapeutic decision. This study aimed to comprehensively investigate the distribution of HER2 kinase domain mutation variants and their association with clinical features and response to chemotherapy in patients with HER 2 mutated advanced NSCLC. We present the following article in accordance with the STROBE reporting checklist (available at http://dx.doi.org/10.21037/tlcr-20-559).

\section{Methods}

\section{Patients population}

Patients with advanced NSCLC and identified with HER2 mutation in Tongji University School of Medicine Thoracic Cancer Institute from January 2015 to November 2018 were collected and reviewed. Detailed clinicopathological characteristics and therapeutic outcomes, such as age, gender, smoking status ("never smoker" was defined as patients with the smoking dose of fewer than 100 cigarettes in their lifetime), tumor histology, TNM stage (IASLC 8th edition), Eastern Cooperative Oncology Group (ECOG) performance status (PS), treatment regimens used, and the outcomes of treatments were collected. In addition, details of brain metastatic status were also collected if available, including the number of lesions, if they were symptomatic or not, and the treatment administrated to brain metastasis. All procedures performed in this study were in accordance with the Declaration of Helsinki (as revised in 2013) and approved by the Ethics Committee of Shanghai Pulmonary Hospital, Tongji University School of Medicine. Because of the retrospective nature of the research, the requirement for informed consent was waived.

\section{Molecular testing}

From January 2015 to November 2018, 2,788 patients of EGFR/ALK/ROS1/KRAS/BRAF wild-type were tested for $H E R 2$ mutations. Molecular testing was performed with the EGFR, BRAF V600, and KRAS Mutations Detection Kit (Amoy Diagnostics, Xiamen, China) based on amplification 
refractory mutation system (ARMS) method, and the AmoyDx EML4-ALK and ROS1 Fusions Detection Kit (Amoy Diagnostics, Xiamen, China) using reverse transcriptase polymerase chain reaction (RT-PCR) per the instructions of manufacturer, respectively. Details are given in our previous reports (11,26,37-39).

HER2 mutation testing was performed with the AmoyDx HER2 Mutation Detection Kit which covered the mutations of exon 19 and exon20, including 13 different base changes encoding 7 different amino acid changes (Amoy Diagnostics, Xiamen, China) using the method of ARMS, following the instructions provided by the manufacturer. Mutation variant detail was identified with DNA sequencing using primers with the following sequences: 5'GCC ATG GCT GTG GTT TGT GAT AGG3' (forward) and 5'ATC CTA GCC CCT TGT GGA CAT AGG3' (reverse), as described in our previous report (11).

\section{Efficacy evaluation of chemotherapy}

Objective tumor responses were determined according to Response Evaluation Criteria in Solid Tumors (RECIST version 1.1). PFS was defined as the time interval from the date of treatment initiation to documented disease progression or death of any cause, whichever occurred first. Patients without disease progression or death were censored. The last date of follow-up was March 15, 2019, and the median follow-up time was 14.1 months. Time to brain metastasis was defined as the time interval from the date of diagnosis to initial documentation of brain metastasis.

\section{Statistical analysis}

Categorical data were analyzed with Chi-square test or Fisher's exact test. Numerical data were analyzed with the Student's $t$-test. The log-rank test was used to compare the survival times between different patient cohorts. Cox proportional hazards regression analysis, hazard ratios (HRs) and $95 \%$ confidential intervals (CIs) were performed and calculated to determine the survival difference. Statistical analyses were performed using the SPSS statistical software (version 20.0; IBM Corporation, Armonk, NY, USA). Gray's test (40) was used to estimate and compare the lifetime incidence of brain metastasis by $\mathrm{R}$ software (version 3.5.2; R Foundation for Statistical Computing, Vienna, Austria). Statistical significance was considered for 2-sided $P$ values of less than 0.05 .

\section{Results}

\section{Patients' characteristics}

Among 2,788 patients without EGFR/ALK/ROS1/KRAS/ $B R A F$ alterations, $4.2 \%(116 / 2,788)$ patients were found to have HER2 mutation using AMRS-PCR method. Among them, 18 patients were excluded from the analysis, including 14 without mutation variant detail due to insufficient tissue sample and 4 without baseline clinicopathological features (Figure 1). Finally, 98 patients were enrolled. Among them, 67 patients were found to harbor YVMA insertion (68.4\%), 14 patients with GSP insertion (14.3\%), 8 patients with G776>VC (8.2\%), 4 patients with G776>LC (4.1\%), 2 patients with G776C (2.0\%), 2 patients with L755P (2.0\%), and 1 patient with V777M (1.0\%) (Figure 2). The median age of enrolled patients was 60 (range, 33-84) years old; 53 (54.1\%) were male; 91 (92.9\%) were with lung adenocarcinoma; 28 (28.6\%) were current/former smokers, and $78(79.6 \%)$ were initially diagnosed as stage IV (Table 1$)$.

Since YVMA insertion accounted for the majority of HER2 mutation, patients were then divided as YVMA group $(n=67)$ and non-YVMA group $(n=31)$. Patients harboring YVMA insertion were found more likely to have extrathoracic metastasis at baseline compared with those in non-YVMA group (40/67, 59.7\% vs. 9/31, 29.0\%, $\mathrm{P}=0.009)$. Among the most prevalent extrathoracic metastatic sites, YVMA group was found to have a significantly higher incidence of brain metastasis $(\mathrm{P}=0.004)$, but not of liver metastasis $(\mathrm{P}=0.053)$ and bone metastasis $(\mathrm{P}=0.112)$. No significant differences in age, gender, histology, ECOG-PS, family cancer history, baseline disease stage and smoking history were observed between the two groups (Table 1).

We also compared the baseline clinicopathological features between patients with HER 2 mutations and patients without common oncogenic alterations (randomly selected, $\mathrm{n}=200$ ). Patients with HER2 mutations displayed a significantly higher proportion of females, young patients, histology as adenocarcinoma and never-smokers compared with patients without common oncodrivers (Tables S1,S2).

\section{Efficacy of first-line chemotherapy between different HER2 mutation variants}

Among 98 patients, $82(83.7 \%)$ received chemotherapy alone as first-line treatment, $6(6.1 \%)$ received targeted therapies including 5 with afatinib and 1 with pyrotinib, $1(1.0 \%)$ received immunotherapy using pembrolizumab, $3(3.1 \%)$ received thoracic radiotherapy either alone or 


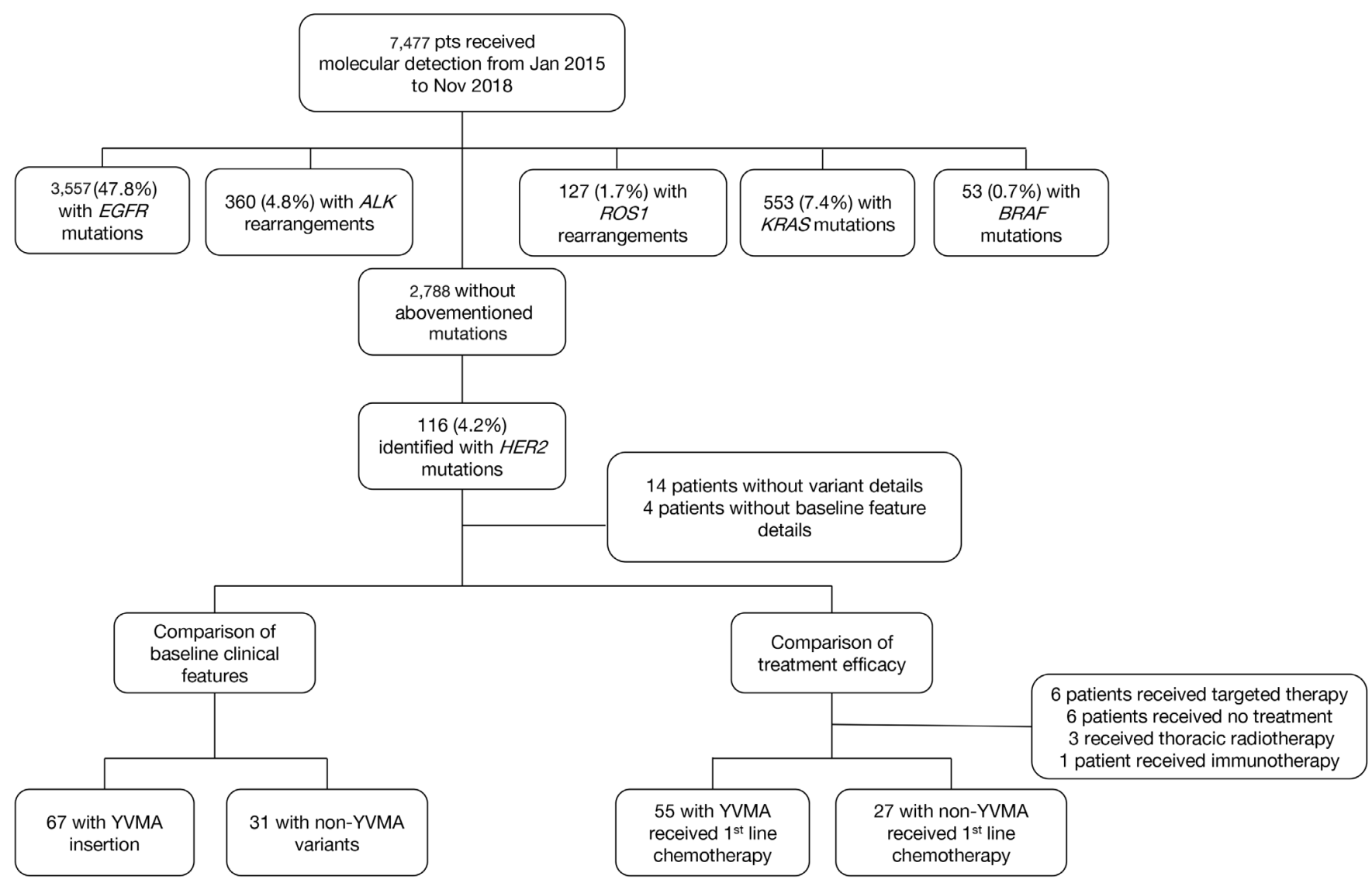

Figure 1 Flowchart of this study. A total of 98 patients were enrolled for comparison of the baseline clinicopathological features, and 82 patients were enrolled for comparison of the efficacy of first line chemotherapy.

combined with chemotherapy, and $6(6.1 \%)$ received no anti-tumor treatment (treatment responses to targeted therapies are summarized in Table S3). Finally, 82 patients were enrolled for chemotherapy efficacy comparison. Among them, 55 (67.1\%) were with YVMA insertion, and $27(32.9 \%)$ with non-YVMA mutation variants. Concerning regimens used, the majority of patients $(78.0 \%, 64 / 82)$ received pemetrexed-based chemotherapy (including 53 combined with platinum, 8 combined with platinum and bevacizumab, and 3 with pemetrexed alone, Table S4). No difference in the chemotherapy regimens was observed between two groups $(\mathrm{P}=0.739)$ (Table 1).

With a median follow-up time as 14.1 months, 73 patients experienced disease progression, while 9 patients were still on chemotherapy at last date of follow-up. The objective response rate (ORR) was $37.8 \%$, and the disease control rate (DCR) was $84.1 \%$ (Table 2). Subgroup analysis showed that YVMA insertion $(\mathrm{n}=55)$ associated with inferior treatment outcomes compared with non-YVMA variants $(\mathrm{n}=27)$ with lower ORR (30.9\% vs. $51.9 \%, \mathrm{P}=0.09)$, lower DCR (78.2\% vs. 96.3\%, $\mathrm{P}=0.051)$, and significantly shorter median PFS (median: 5.2 vs. 7.7 months, $\mathrm{P}=0.038$ ) (Table 2, Figure 3). Similarly, YVMA insertion $(\mathrm{n}=40)$ was also observed with inferior treatment outcomes, with lower ORR (31.8\% vs. $60.0 \%, \mathrm{P}=0.054)$, lower DCR (75.0\% vs. $95.0 \%, \mathrm{P}=0.085)$, and a significantly shorter median PFS (5.2 vs. 6.5 months, $\mathrm{P}=0.022)$ than non-YVMA variants $(\mathrm{n}=24)$ in patients received pemetrexed-based chemotherapy $(n=64)$. In addition, we also compared the efficacy of chemotherapy between patients with HER2 mutation $(\mathrm{n}=82)$ and patients without common oncogenic mutations (randomly selected, $\mathrm{n}=50$ ), no significant differences in ORR (37.8\% vs. $28 \%$, $\mathrm{P}=0.264)$, DCR $(84.1 \%$ vs. $82 \%, \mathrm{P}=0.812)$ and median PFS (median: 5.8 vs. 5.1 months, $\mathrm{P}=0.922$ ) were observed (Table S2).

Multivariate cox regression analysis, incorporating age, gender, histology, smoking history, ECOG PS, mutation variants group, and baseline disease involvement found 


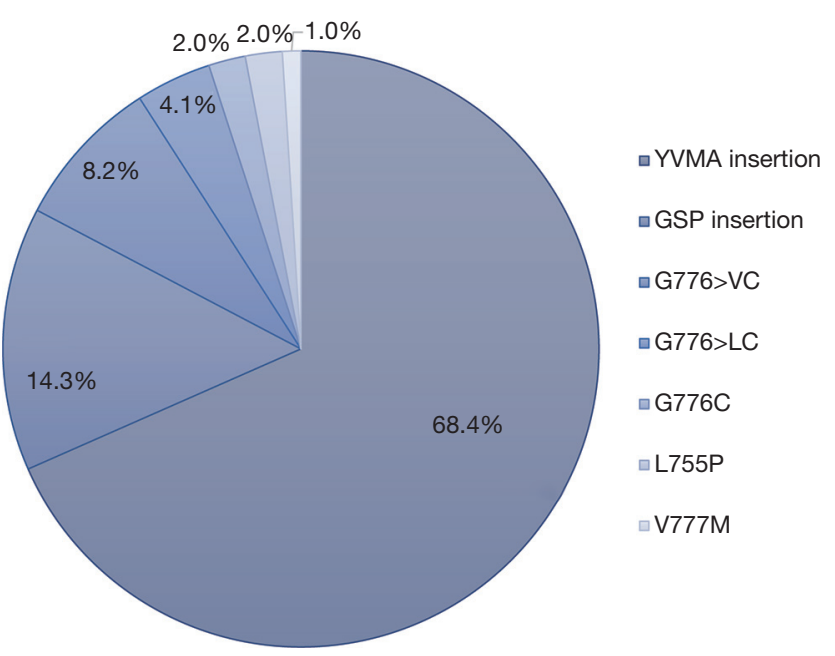

Figure 2 The spectrum of mutation variants of HER2 kinase domain of the enrolled 98 patients. that patients with YVMA insertion associated with worse PFS compared with patients of non-YVMA variants both in total patients (HR $=1.578,95 \% \mathrm{CI}, 0.956-2.606)$ and subgroup of pemetrexed-based chemotherapy (HR $=1.789$, 95\% CI, 1.013-3.160) (Table 3). Since baseline extrathoracic metastases also associated with worse PFS in both the whole population and the pemetrexed subgroup, we then further performed multivariate analysis incorporating the most prevalent metastatic sites and found baseline bone metastases associated with worse PFS (HR $=1.788$, 95\% CI, 1.072-2.981) and YVMA also associated with worse PFS (HR =1.633, 95\% CI, 0.985-2.706). Similarly, subgroup analysis also showed YVMA insertion to be associated with worse PFS (HR $=1.685,95 \%$ CI, 0.931 3.051) in patients treated with pemetrexed-based regimens (Table S5).

Table 1 Baseline clinicopathological features and treatment regimens used in total patients and two groups.

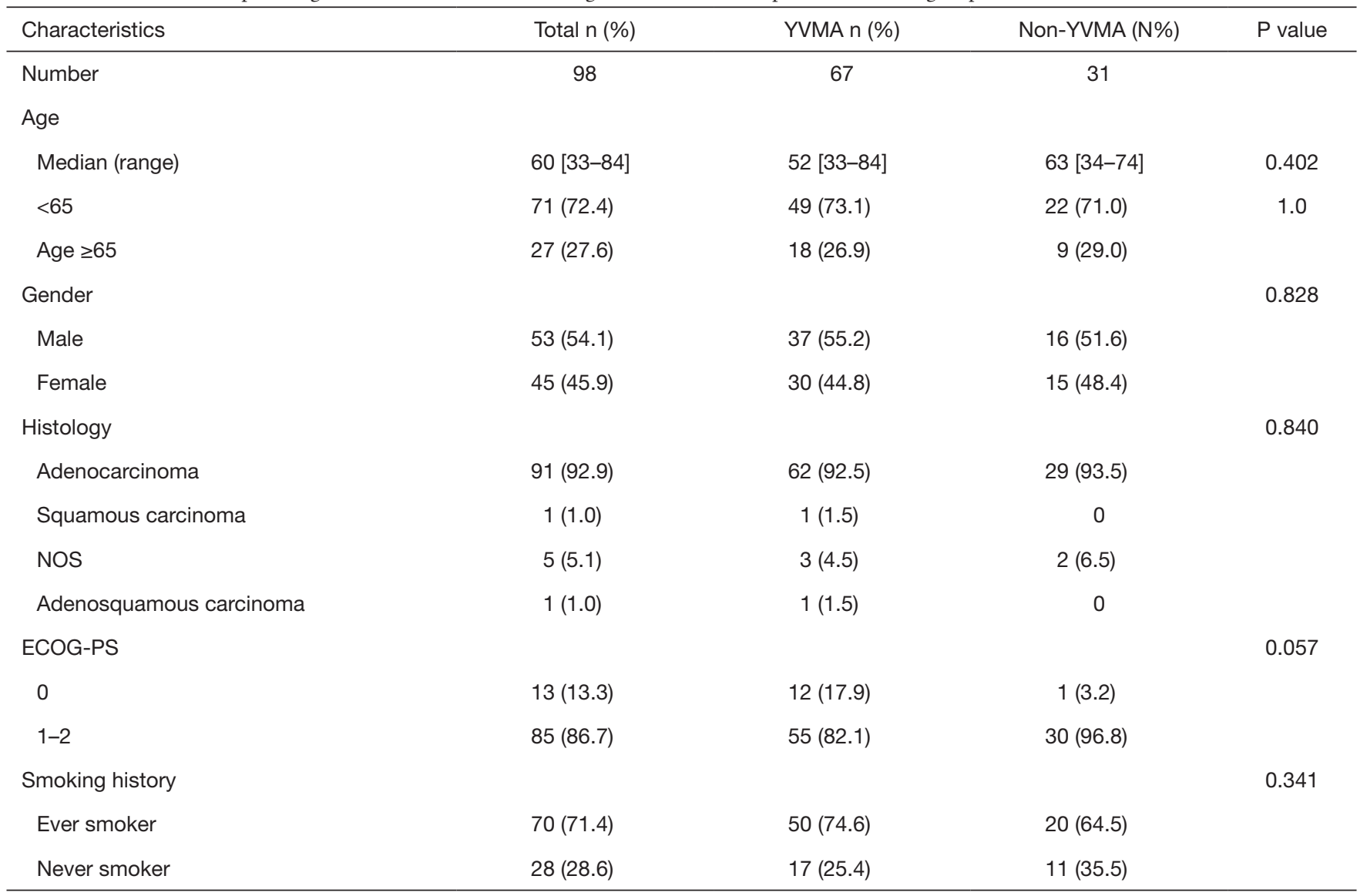

Table 1 (continued) 


\begin{tabular}{|c|c|c|c|c|}
\hline Characteristics & Total n (\%) & YVMA n (\%) & Non-YVMA (N\%) & $P$ value \\
\hline Stage of disease & & & & 0.925 \\
\hline$\| I I B / I I C$ & $12(12.2)$ & $8(11.9)$ & $4(12.9)$ & \\
\hline IVA/IVB & $78(79.6)$ & $54(80.6)$ & $24(77.4)$ & \\
\hline Recurrent & $8(8.2)$ & $5(7.5)$ & $3(9.7)$ & \\
\hline Disease involvement & & & & 0.009 \\
\hline Intrathoracic & $49(50.0)$ & $27(40.3)$ & $22(71.0)$ & \\
\hline Extrathoracic & $49(50.0)$ & $40(59.7)$ & $9(29.0)$ & \\
\hline \multicolumn{5}{|l|}{ Prevalent metastatic sites } \\
\hline Brain & $14(14.3)$ & $14(20.9)$ & 0 & 0.004 \\
\hline Liver & $8(8.2)$ & $8(11.9)$ & 0 & 0.053 \\
\hline Bone & $34(34.7)$ & $27(40.3)$ & $7(22.6)$ & 0.112 \\
\hline Treatment as first line & & & & NE \\
\hline Chemotherapy & $82(83.7)$ & 55 (82.1) & $27(87.1)$ & \\
\hline Targeted therapy & $6(6.1)$ & $6(9.0)$ & 0 & \\
\hline Immunotherapy & $1(1.0)$ & $1(1.5)$ & 0 & \\
\hline Unknown or without systemic treatment & $9(9.2)$ & $5(7.5)$ & $4(12.9)$ & \\
\hline Chemotherapy regimens & & & & 0.739 \\
\hline Pemetrexed based & $64(78.0)$ & $44(80.0)$ & $20(74.1)$ & \\
\hline Gemcitabine based & $14(17.1)$ & $8(14.5)$ & $6(22.2)$ & \\
\hline Paclitaxel based & $4(4.9)$ & $3(5.5)$ & $1(3.7)$ & \\
\hline
\end{tabular}

NOS, not other specified; ECOG-PS, Eastern Cooperative Oncology Group Performance Score.

\section{Correlation of HER2 mutation variants with the incidence of brain metastases}

Since brain metastasis was found to be significantly much more prevalent in patients with YVMA insertion than in other patients, we then investigated the impact of mutation variants on the incidence of lifetime brain metastasis. Among 98 patients enrolled, 14 (14.3\%) were found with baseline brain metastasis, and all of them were with YVMA insertion ( $\mathrm{P}=0.004)$. The majority of patients $(8 / 14,57.1 \%)$ with baseline brain metastasis were with limited lesions (1-3) and asymptomatic brain metastasis (10/14, 71.4\%). Among the four patients with symptomatic brain metastasis, three patients received cranial radiotherapy, including two with WBRT plus SRS and one with WBRT alone, and one patient received surgical resection of metastatic brain lesion as initial treatment (detailed information of treatments used in patients with brain metastases were presented as Table S6). Together, 34 (34/98, 34.7\%) patients developed brain metastasis during lifetime, including 29 with YVMA insertion and 5 with non-YVMA variants. YVMA insertion associated with a significantly higher incidence of lifetime brain metastasis $(85.3 \%$ vs. $14.7 \%, \mathrm{P}=0.012)$ than patients with non-YVMA variants (Table 4).

Since patient's death was a competitive factor for the development of brain metastasis, we then performed Gray's test (40) to estimate and compare the incidence of lifetime brain metastasis between the two groups. When adjusted for death, YVMA insertion still showed a significantly higher incidence of brain metastasis compared with nonYVMA variants $(\mathrm{P}=0.002)$, with an estimated 12 -month brain metastasis incidence as $40.2 \%$ in the YVMA group and $3.6 \%$ in the non-YVMA group (Figure 4). While for 
Table 2 Efficacy of first line chemotherapy of total patients and patients treated with pemetrexed based chemotherapy

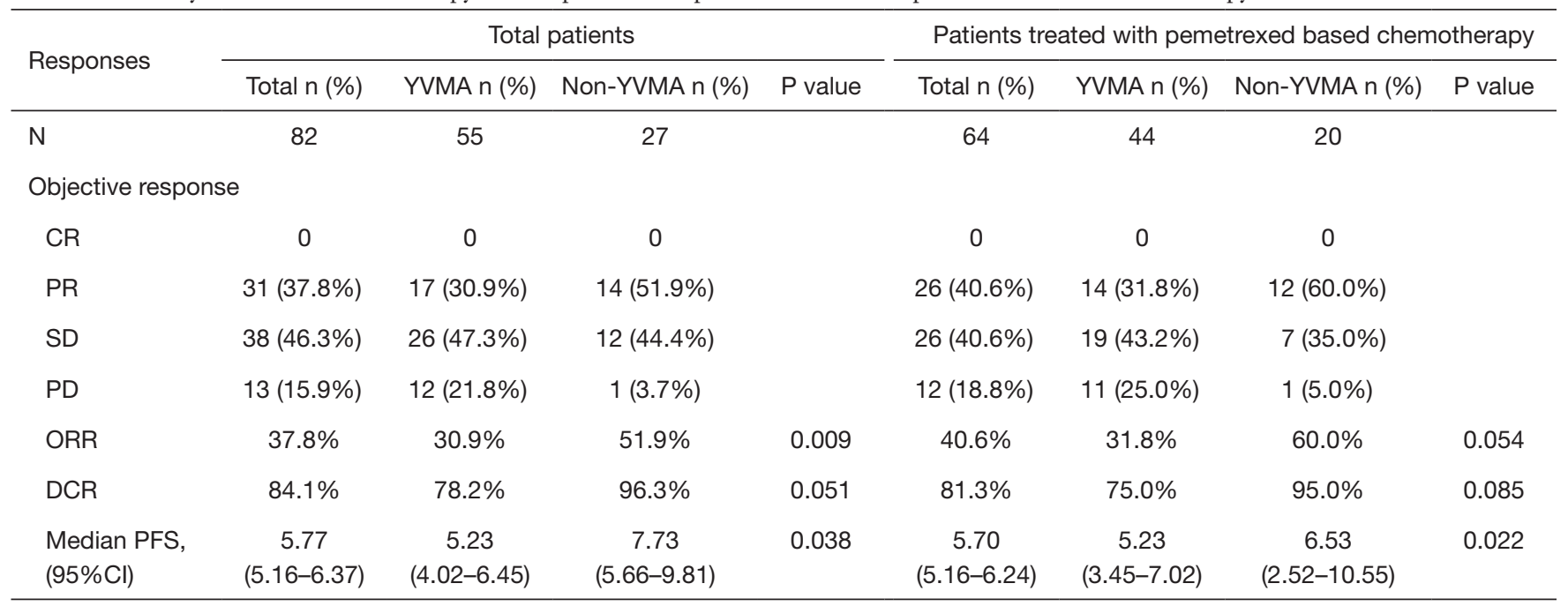

$\mathrm{CR}$, complete response; PR, partial response; SD, stable disease; PD, progressive disease; ORR, objective response rate; DCR, disease control rate; PFS, progression free survival; $\mathrm{Cl}$, confidential interval.
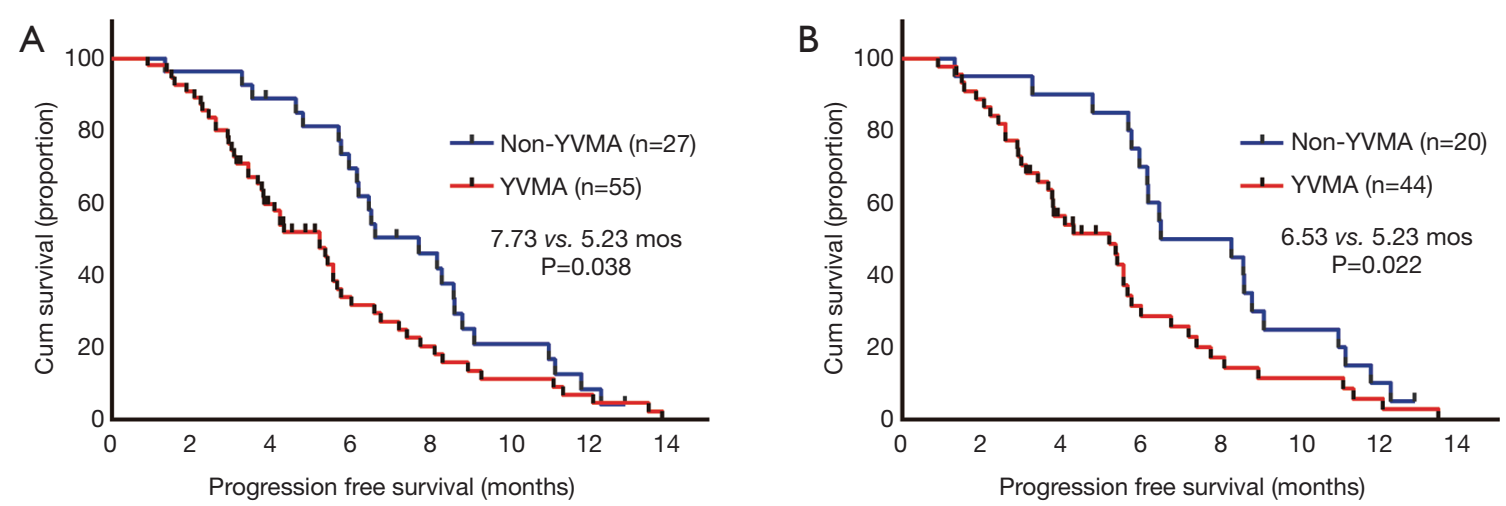

Figure 3 Comparison of PFS according to HER2 mutation variants. (A) PFS of patients who received chemotherapy as first line treatment $(n=82)$. (B) PFS of patients who received pemetrexed based chemotherapy as first-line treatment $(n=64)$.

cumulative brain metastasis incidence, YVMA insertion also associated with higher incidence of 12 -month brain metastasis incidence as $24.4 \%$ compared with $3.6 \%$ in the non-YVMA group with marginal significance $(\mathrm{P}=0.064)$.

We also compared the baseline clinicopathological features of patients with and without brain metastasis. We found that patients with baseline brain metastasis were significantly younger (median age: 50 vs. 61 years) $(\mathrm{P}=0.007)$, and patients with lifetime brain metastasis were also significantly younger $(\mathrm{P}=0.009)$. No significant differences in gender, histology, ECOG-PS, and smoking status were observed between the two groups (Table 4).

Discussion
To the best of our knowledge, this study was the first to investigate the association of HER2 mutation variants with clinical features and efficacy of chemotherapy. We found that YVMA insertion accounted for the majority of patients with HER2 kinase domain mutations and was associated with inferior treatment outcomes compared with patients with non-YVMA variants. We also found YVMA insertion associated with more extrathoracic disease, notably with a significantly higher incidence of baseline brain metastasis.

In our study, the incidence of HER2 kinase domain mutations in advanced NSCLC was $4.2 \%$ for patients without common oncogenic mutations, which was in line 
Table 3 Multivariate analysis for total patients and patients with pemetrexed based chemotherapy

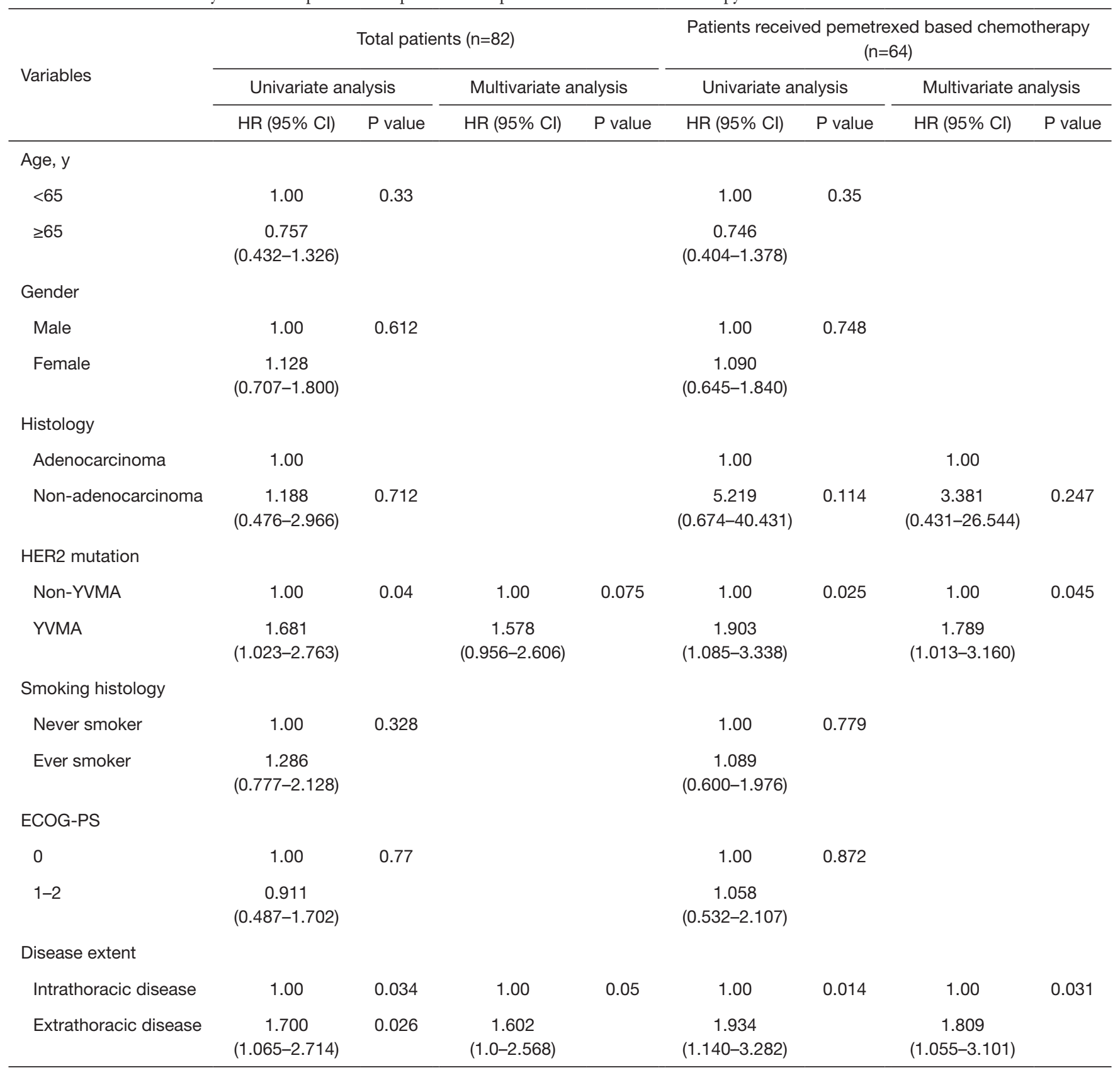

ECOG-PS, Eastern Cooperative Oncology Group Performance Score; HR, hazard ratio; CI, confidential interval.

with our previous studies $(11,41)$ and comparable to the $6 \%$ reported by Arcila et al. in a selected population of EGFR/KRAS/ALK-negative patients mainly consisting of Caucasians (42). Consistent with our previous reports $(11,41)$, we also found that patients with HER2 kinase domain mutations were more likely to be females, younger patients, never-smokers and adenocarcinoma when compared with patients without oncogenic gene alterations. Among them, A775_G776insYVMA accounted for 68.4\% $(67 / 98)$ of patients enrolled, consistent with percentage as 65-100\% of HER2-mutated NSCLC patients reported by previous studies $(9,24,41-43)$.

Increasing evidence has already demonstrated that driver gene mutation variants have distinct clinical features, 
Table 4 Clinicopathological features of patients with and without baseline brain metastasis and lifetime brain metastasis

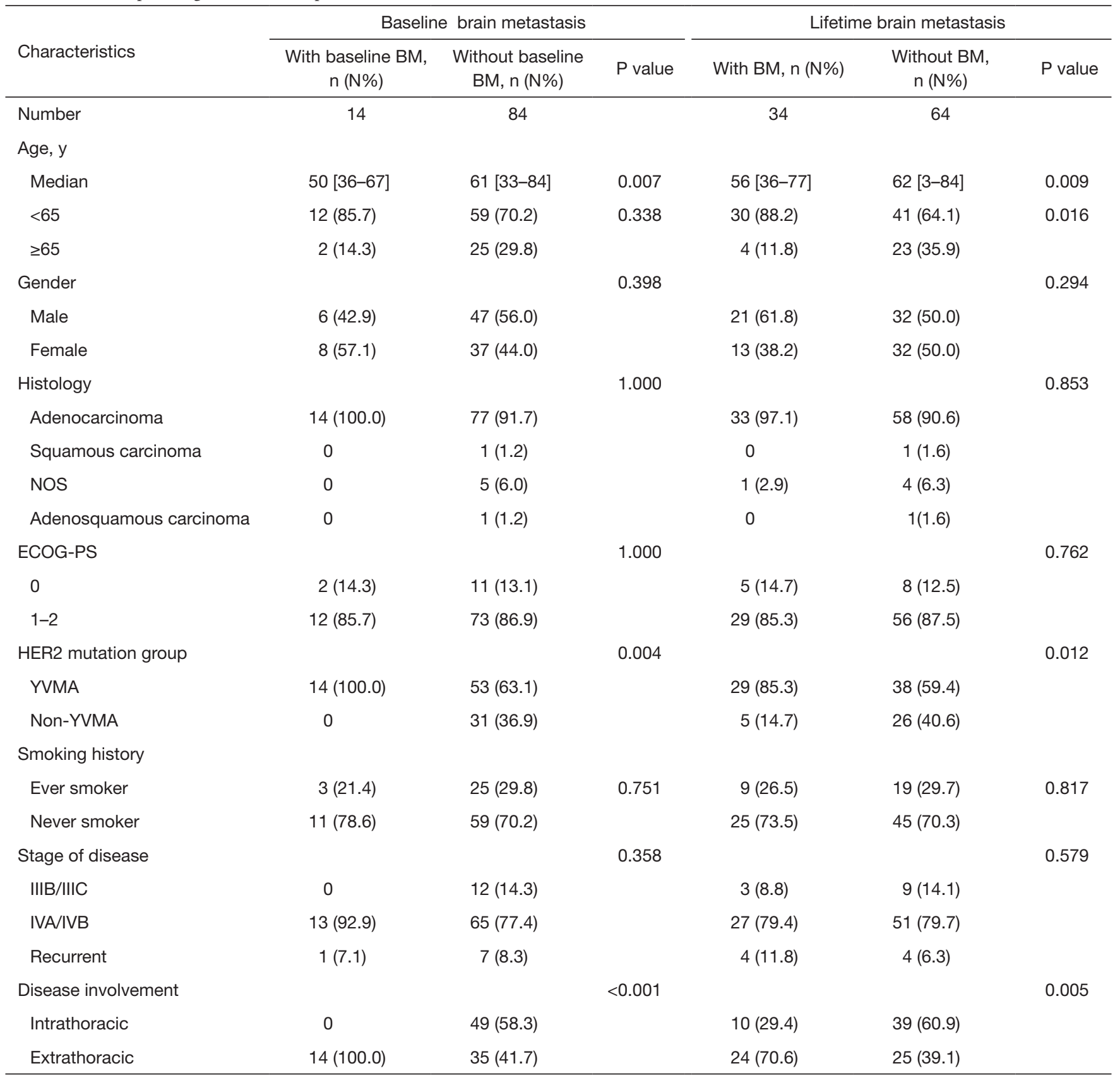

NOS, not other specified; ECOG-PS, Eastern Cooperative Oncology Group Performance Score.

treatment outcomes, and resistance mechanisms to treatments (28,29,31-34). Recently, Hastings et al. further found that patients with EGFR L858R benefited more from immunotherapy than patients with exon 19 deletion, which could derive from the higher tumor mutation burden observed in patients with EGFR L858R (35). Christopoulos et al. also showed that the incidence of $\mathrm{p} 53$ co-mutation was higher in the $E M L-A L K$ variant 3, which might account for its miserable prognosis and diminished outcomes to treatments (44). As for HER2 mutations, discrepant efficacy has also been observed regarding different variants. In vitro studies observed that YVMA insertion has a different sensitivity to targeted therapy compared with other HER2 mutation variants $(12,45)$. A phase II trial investigated the 

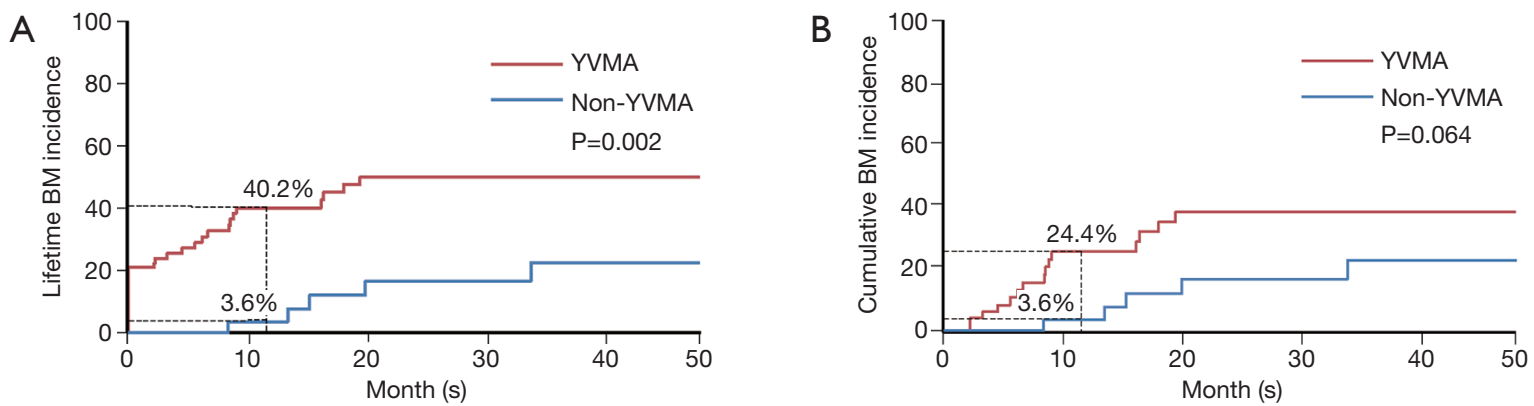

Figure 4 Comparison of lifetime brain metastases incidence and cumulative brain metastasis incidence according to HER2 mutation variants in a total of 98 patients. The estimated 12-month brain metastases incidence was also indicated. BM, brain metastasis.

efficacy of afatinib on HER2-mutated NSCLC and found YVMA to be associated with superior efficacy, with $7 / 11$ patients achieving disease control at 12 weeks compared with 0/1 patient with G776>VC (46). While in several other studies, YVMA insertion were found to associate with inferior treatment efficacy. Recently, a study by Zhang and colleagues demonstrated that G778_P780dup and G776delinsVC derived the greatest benefits from afatinib among HER2 variants (36). Same was also observed in patients treated with pyrotinib, showing that patients with 9-bp exon 20 insertion associated with higher ORR than patients with 12-bp exon 20 insertion (19).

Currently, although targeted therapies hold great potential, chemotherapy remains the cornerstone for patients with advanced HER2-mutated NSCLC. The association of HER2 mutation variants with chemotherapy and clinicopathological features needs to be further clarified. In the current study, we, for the first time, reported that patients harboring YVMA insertion displayed inferior outcomes to first-line chemotherapy, with worse ORR, DCR, and median PFS compared with non-YVMA variants. Multivariate analysis further confirmed the association of YVMA insertion with worse PFS, especially for patients received pemetrexed-based chemotherapy $(\mathrm{HR}=1.789$, 95\% CI, 1.013-3.160). In addition, we found extrathoracic metastases to be associated with worse PFS both in the univariate and multivariate analysis. Since patients with YVMA insertion showed a significantly higher incidence of extrathoracic metastases, the reason that patients harboring YVMA insertion benefit less from first line chemotherapy might due to their discrepancy of metastases, which further emphasized the unmet need of new therapeutic strategies for patients with YVMA insertion.

Brain metastasis is a major obstacle hindering the achievement of durable response. In our study, the incidence of baseline brain metastasis was $14.3 \%$, and $34.7 \%$ (34/98) patients developed brain metastasis during their lifetime. We found that YVMA insertion associated with a significantly higher incidence of baseline brain metastasis, and Gray's test further established that YVMA insertion associated with a significantly higher incidence of lifetime brain metastasis compared with non-YVMA variants. Nowadays, several second- or third-generation targeted drugs with higher blood-brain barrier (BBB) penetration capacity have shown superior efficacy in treating and postponing the onset of brain metastasis and have become the standard treatment of patients harboring EGFR/ALK alterations (47). In the current study, we, for the first time, identified the 12-month brain metastasis incidence as $40.2 \%$ in the YVMA group and $3.6 \%$ in the non-YVMA group, indicating that almost 2/5 patients with YVMA insertion might develop brain metastasis during their lifetime. In the current study, we also found that patients with baseline brain metastasis showed a shorter median PFS compared with patients without brain metastasis (median PFS: 3.1 vs. 5.9 months, $\mathrm{P}=0.280$ ), even in patients with YVMA mutations alone (median PFS: 3.1 vs. 5.4 months, $\mathrm{P}=0.632)$. It is, therefore, imperative to develop targeted drugs with high $\mathrm{BBB}$ penetration capacity for patients of advanced NSCLC with HER2 mutations, especially for those harboring YVMA insertion.

Several limitations must be mentioned. First, as a retrospective study, the selection bias was inevitable, and the relatively small sample size potentially limited our ability to draw affirmative conclusions. Second, although we have thoroughly reviewed medical records and collected all the information available, the real-world feature of this study might underestimate the incidence of brain metastases. Studies with a large patient number are warranted to further verify our findings. Third, HER2 mutations were detected using ARMS-PCR, which was designed to detect 
only mutations within exon19 and exon20 of HER2 kinase domain; thus rare mutations such as $\mathrm{S} 310 \mathrm{~F}$ of extracellular domain (48), V659/G660 mutation of transmembrane domain (49), and other rare HER2 mutations which also have been demonstrated oncogenic and druggable might be missed. In addition, we did not routinely detect p53 mutation in our institute, and further studies using nextgeneration sequencing (NGS) are needed to further clarify the spectrum of HER2 mutations and the incidence of comutations in different mutation variants.

In conclusion, our study demonstrated that the HER2 exon 20 YVMA insertion significantly associates with aggressive disease, notably with a significantly higher incidence of both baseline and lifetime brain metastasis, together with inferior outcomes of first-line chemotherapy. Our finding indicates that more potent anti-cancer therapies with high $\mathrm{BBB}$ penetration capacity are needed, especially for patients with HER2 exon 20 YVMA insertion.

\section{Acknowledgments}

We thank all patients that were involved in this study. We thank Prof. Likun Hou and Prof. Chunyan Wu of Department of Pathology of Shanghai Pulmonary Hospital for technical assistance. We thank LetPub (www.letpub. com) for its linguistic assistance during the preparation of this manuscript.

Funding: This study was supported in part by grants from Shanghai Municipal Education Commission (No. 16SG18), the Science and Technology Commission of Shanghai Municipality (No. 16411964600), the National Natural Science Foundation of China (No. 81772467), the Shanghai Shen Kang Hospital Development Center (No. SHDC 12015314), and the Backbone Program of Shanghai Pulmonary Hospital (No. FKGG1802).

\section{Footnote}

Reporting Checklist: The authors have completed the STROBE reporting checklist. Available at http://dx.doi. org/10.21037/tlcr-20-559

Data Sharing Statement: Available at http://dx.doi. org/10.21037/tlcr-20-559

Conflicts of Interest: All authors have completed the ICMJE uniform disclosure form (available at http://dx.doi. org/10.21037/tlcr-20-559). CZ serves as an unpaid editorial board member of Translational Lung Cancer Research from Aug 2020 to Jul 2022. The other authors have no conflicts of interest to declare.

Etbical Statement: The authors are accountable for all aspects of the work in ensuring that questions related to the accuracy or integrity of any part of the work are appropriately investigated and resolved. All procedures performed in this study were in accordance with the Declaration of Helsinki (as revised in 2013) and approved by the Ethics Committee of Shanghai Pulmonary Hospital, Tongji University School of Medicine. Because of the retrospective nature of the research, the requirement for informed consent was waived.

Open Access Statement: This is an Open Access article distributed in accordance with the Creative Commons Attribution-NonCommercial-NoDerivs 4.0 International License (CC BY-NC-ND 4.0), which permits the noncommercial replication and distribution of the article with the strict proviso that no changes or edits are made and the original work is properly cited (including links to both the formal publication through the relevant DOI and the license). See: https://creativecommons.org/licenses/by-nc-nd/4.0/.

\section{References}

1. Zhou C, Wu YL, Chen G, et al. Erlotinib versus chemotherapy as first-line treatment for patients with advanced EGFR mutation-positive non-small-cell lung cancer (OPTIMAL, CTONG-0802): a multicentre, open-label, randomised, phase 3 study. Lancet Oncol 2011;12:735-42.

2. Peters S, Camidge DR, Shaw AT, et al. Alectinib versus Crizotinib in Untreated ALK-Positive Non-Small-Cell Lung Cancer. N Engl J Med 2017;377:829-38.

3. Shaw AT, Ou SH, Bang YJ, et al. Crizotinib in ROS1rearranged non-small-cell lung cancer. N Engl J Med 2014;371:1963-71.

4. Planchard D, Smit EF, Groen HJM, et al. Dabrafenib plus trametinib in patients with previously untreated BRAF(V600E)-mutant metastatic non-small-cell lung cancer: an open-label, phase 2 trial. Lancet Oncol 2017;18:1307-16.

5. National Comprehensive Cancer Network. (NCCN) Clinical Practice Guidelines in Oncology. Non-small Cell Lung Cancer, Version 2. 2019. Available online: https:// www.nccn.org/professionals/physician_gls/pdf/nscl.pdf. 
Accessed 26 Feb 2019

6. Wu YL, Planchard D, Lu S, et al. Pan-Asian adapted Clinical Practice Guidelines for the management of patients with metastatic non-small-cell lung cancer: a CSCO-ESMO initiative endorsed by JSMO, KSMO, MOS, SSO and TOS. Ann Oncol 2019;30:171-210.

7. Planchard D, Popat S, Kerr K, et al. Metastatic non-small cell lung cancer: ESMO Clinical Practice Guidelines for diagnosis, treatment and follow-up. Ann Oncol 2018;29:iv192-iv237.

8. AMG 510 First to Inhibit "Undruggable" KRAS. Cancer Discov 2019;9:988-9.

9. Shigematsu H, Takahashi T, Nomura M, et al. Somatic mutations of the HER2 kinase domain in lung adenocarcinomas. Cancer Res 2005;65:1642-6.

10. Wang SE, Narasanna A, Perez-Torres M, et al. HER2 kinase domain mutation results in constitutive phosphorylation and activation of HER2 and EGFR and resistance to EGFR tyrosine kinase inhibitors. Cancer Cell 2006;10:25-38.

11. Li X, Zhao C, Su C, et al. Epidemiological study of HER2 mutations among EGFR wild-type lung adenocarcinoma patients in China. BMC Cancer 2016;16:828.

12. Koga T, Kobayashi Y, Tomizawa K, et al. Activity of a novel HER2 inhibitor, poziotinib, for HER2 exon 20 mutations in lung cancer and mechanism of acquired resistance: An in vitro study. Lung Cancer 2018;126:72-9.

13. Li BT, Shen R, Buonocore D, et al. Ado-Trastuzumab Emtansine for Patients With HER2-Mutant Lung Cancers: Results From a Phase II Basket Trial. J Clin Oncol 2018;36:2532-7.

14. Janne P, Li B, Murakami H, et al. A Phase 2 Study of DS-8201a in HER2-Overexpressing or -Mutated Advanced Non-Small-Cell Lung Cancer. J Thorac Oncol 2018;13:S476.

15. Wang Y, Jiang T, Qin Z, et al. HER2 exon 20 insertions in non-small-cell lung cancer are sensitive to the irreversible pan-HER receptor tyrosine kinase inhibitor pyrotinib. Ann Oncol 2019;30:447-55.

16. Doebele RC, Riely GJ, Spira AI, et al. First report of safety, $\mathrm{PK}$, and preliminary antitumor activity of the oral EGFR/HER2 exon 20 inhibitor TAK-788 (AP32788) in non-small cell lung cancer (NSCLC). J Clin Oncol 2018;36:2.

17. Hyman DM, Piha-Paul SA, Won H, et al. HER kinase inhibition in patients with HER2 - and HER3-mutant cancers. Nature 2018;554:189-94.

18. Robichaux JP, Elamin YY, Tan Z, et al. Mechanisms and clinical activity of an EGFR and HER2 exon 20-selective kinase inhibitor in non-small cell lung cancer. Nat Med 2018;24:638-46.

19. Zhou C, Li X, Wang Q, et al. Pyrotinib in HER2-Mutant Advanced Lung Adenocarcinoma After Platinum-Based Chemotherapy: A Multicenter, Open-Label, Single-Arm, Phase II Study. J Clin Oncol 2020;38:2753-61.

20. Peters S, Stahel R, Bubendorf L, et al. Trastuzumab Emtansine (T-DM1) in Patients with Previously Treated HER2-Overexpressing Metastatic Non-Small Cell Lung Cancer: Efficacy, Safety, and Biomarkers. Clin Cancer Res 2019;25:64-72.

21. Hotta K, Aoe K, Kozuki T, et al. A Phase II Study of Trastuzumab Emtansine in HER2-Positive Non-Small Cell Lung Cancer. J Thorac Oncol 2018;13:273-9.

22. Tsurutani J, Iwata H, Krop I, et al. Targeting HER2 with Trastuzumab Deruxtecan: A Dose-Expansion, Phase I Study in Multiple Advanced Solid Tumors. Cancer Discov 2020;10:688-701.

23. Li BT, Michelini F, Misale S, et al. HER2-Mediated Internalization of Cytotoxic Agents in ERBB2 Amplified or Mutant Lung Cancers. Cancer Discov 2020;10:674-87.

24. Mazieres J, Barlesi F, Filleron T, et al. Lung cancer patients with HER2 mutations treated with chemotherapy and HER2-targeted drugs: results from the European EUHER2 cohort. Ann Oncol 2016;27:281-6.

25. Hellmann MD, Li BT, Chaft JE, et al. Chemotherapy remains an essential element of personalized care for persons with lung cancers. Ann Oncol 2016;27:1829-35.

26. Li X, Cai W, Yang G, et al. Comprehensive Analysis of EGFR-Mutant Abundance and Its Effect on Efficacy of EGFR TKIs in Advanced NSCLC with EGFR Mutations. J Thorac Oncol 2017;12:1388-97.

27. Zhou J, Ben S. Comparison of therapeutic effects of EGFR-tyrosine kinase inhibitors on 19Del and L858R mutations in advanced lung adenocarcinoma and effect on cellular immune function. Thorac Cancer 2018;9:228-33.

28. Yoshida T, Oya Y, Tanaka K, et al. Differential Crizotinib Response Duration Among ALK Fusion Variants in ALKPositive Non-Small-Cell Lung Cancer. J Clin Oncol 2016;34:3383-9.

29. Woo CG, Seo S, Kim SW, et al. Differential protein stability and clinical responses of EML4-ALK fusion variants to various ALK inhibitors in advanced ALKrearranged non-small cell lung cancer. Ann Oncol 2017;28:791-7.

30. Lin JJ, Zhu VW, Yoda S, et al. Impact of EML4ALK Variant on Resistance Mechanisms and Clinical 
Outcomes in ALK-Positive Lung Cancer. J Clin Oncol 2018;36:1199-206.

31. Dagogo-Jack I, Martinez P, Yeap BY, et al. Impact of BRAF Mutation Class on Disease Characteristics and Clinical Outcomes in BRAF-mutant Lung Cancer. Clin Cancer Res 2019;25:158-65.

32. Christopoulos P, Endris V, Bozorgmehr F, et al. EML4ALK fusion variant $\mathrm{V} 3$ is a high-risk feature conferring accelerated metastatic spread, early treatment failure and worse overall survival in $\mathrm{ALK}(+)$ non-small cell lung cancer. Int J Cancer 2018;142:2589-98.

33. Christopoulos P, Budczies J, Kirchner M, et al. Defining molecular risk in ALK(+) NSCLC. Oncotarget 2019; 10:3093-103.

34. Ke EE, Zhou Q, Zhang QY, et al. A Higher Proportion of the EGFR T790M Mutation May Contribute to the Better Survival of Patients with Exon 19 Deletions Compared with Those with L858R. J Thorac Oncol 2017;12:1368-75.

35. Hastings $\mathrm{K}$, Yu H, Wei W, et al. EGFR mutation subtypes and response to immune checkpoint blockade treatment in non-small cell lung cancer. Ann Oncol 2019;30:1311-20.

36. Fang W, Zhao S, Liang Y, et al. Mutation Variants and CoMutations as Genomic Modifiers of Response to Afatinib in HER2-Mutant Lung Adenocarcinoma. Oncologist 2020;25:e545-54.

37. Zhang L, Jiang T, Li X, et al. Clinical features of Bim deletion polymorphism and its relation with crizotinib primary resistance in Chinese patients with ALK/ROS1 fusion-positive non-small cell lung cancer. Cancer 2017;123:2927-35.

38. Wu C, Zhao C, Yang Y, et al. High Discrepancy of Driver Mutations in Patients with NSCLC and Synchronous Multiple Lung Ground-Glass Nodules. J Thorac Oncol 2015;10:778-83.

39. Wang Y, Zhang J, Gao G, et al. EML4-ALK Fusion Detected by RT-PCR Confers Similar Response to Crizotinib as Detected by FISH in Patients with Advanced Non-Small-Cell Lung Cancer. J Thorac Oncol 2015;10:1546-52.

40. Fine JP, Gray RJ. A Proportional Hazards Model for the Subdistribution of a Competing Risk. J Am Stat Assoc 1999;94:496-509.

41. Wang Y, Zhang S, Wu F, et al. Outcomes of Pemetrexedbased chemotherapies in HER2-mutant lung cancers. BMC Cancer 2018;18:326.
42. Arcila ME, Chaft JE, Nafa K, et al. Prevalence, clinicopathologic associations, and molecular spectrum of ERBB2 (HER2) tyrosine kinase mutations in lung adenocarcinomas. Clin Cancer Res 2012;18:4910-8.

43. Pillai RN, Behera M, Berry LD, et al. HER2 mutations in lung adenocarcinomas: A report from the Lung Cancer Mutation Consortium. Cancer 2017;123:4099-105.

44. Christopoulos P, Dietz S, Kirchner M, et al. Detection of TP53 Mutations in Tissue or Liquid Rebiopsies at Progression Identifies ALK+ Lung Cancer Patients with Poor Survival. Cancers (Basel) 2019;11:124.

45. Kosaka T, Tanizaki J, Paranal RM, et al. Response Heterogeneity of EGFR and HER2 Exon 20 Insertions to Covalent EGFR and HER2 Inhibitors. Cancer Res 2017;77:2712-21.

46. Dziadziuszko R, Smit EF, Dafni U, et al. Afatinib in NSCLC With HER2 Mutations: Results of the Prospective, Open-Label Phase II NICHE Trial of European Thoracic Oncology Platform (ETOP). J Thorac Oncol 2019;14:1086-94.

47. Martinez P, Mak RH, Oxnard GR. Targeted Therapy as an Alternative to Whole-Brain Radiotherapy in EGFRMutant or ALK-Positive Non-Small-Cell Lung Cancer With Brain Metastases. JAMA Oncol 2017;3:1274-5.

48. Greulich H, Kaplan B, Mertins P, et al. Functional analysis of receptor tyrosine kinase mutations in lung cancer identifies oncogenic extracellular domain mutations of ERBB2. Proc Natl Acad Sci U S A 2012;109:14476-81.

49. Ou SI, Schrock AB, Bocharov EV, et al. HER2 Transmembrane Domain (TMD) Mutations (V659/ G660) That Stabilize Homo- and Heterodimerization Are Rare Oncogenic Drivers in Lung Adenocarcinoma That Respond to Afatinib. J Thorac Oncol 2017;12:446-57.

Cite this article as: Yang S, Wang Y, Zhao C, Li X, Liu Q, Mao S, Liu Y, Yu X, Wang W, Tian Q, Pan Y, Xiong A, Chen B, Gao G, Li W, He Y, Wu F, Chen X, Su C, Ren S, Zhou C. Exon 20 YVMA insertion is associated with high incidence of brain metastasis and inferior outcome of chemotherapy in advanced non-small cell lung cancer patients with HER2 kinase domain mutations. Transl Lung Cancer Res 2021;10(2):753765. doi: $10.21037 /$ tlcr-20-559 


\section{Supplementary}

Table S1 Comparison of baseline clinicopathological features of patients with HER2 mutations and patients without oncodriver mutations

\begin{tabular}{|c|c|c|c|c|}
\hline \multirow{2}{*}{ Characteristics } & total n (N\%) & HER2 mutation n (N\%) & $\begin{array}{l}\text { without HER2 mutation } \\
\qquad \mathrm{n}(\mathrm{N} \%)\end{array}$ & \multirow{2}{*}{$p$ value } \\
\hline & 298 & 98 & 200 & \\
\hline male & $209(70.1 \%)$ & $53(54.1 \%)$ & $156(78.0 \%)$ & \multirow[t]{2}{*}{$<0.001$} \\
\hline female & $89(29.9 \%)$ & 45 (45.9\%) & $44(22.0 \%)$ & \\
\hline median (range) & $63.7(32-86)$ & $60.0(33-83)$ & $65.0(32-86)$ & $<0.001$ \\
\hline$<65$ & $168(56.4 \%)$ & $71(72.4 \%)$ & $97(48.5 \%)$ & \multirow[t]{2}{*}{$<0.001$} \\
\hline$\geq 65$ & $130(43.6 \%)$ & $27(27.6 \%)$ & $103(51.5 \%)$ & \\
\hline adenosquamous carcinoma & $2(0.7 \%)$ & $1(1.0 \%)$ & $1(0.5 \%)$ & \multirow{2}{*}{$<0.001$} \\
\hline NOS & $60(20.1 \%)$ & $5(5.1 \%)$ & $55(27.5 \%)$ & \\
\hline \multicolumn{5}{|l|}{ Smoking history } \\
\hline never-smoker & $187(62.8 \%)$ & $70(71.4 \%)$ & $117(58.5 \%)$ & \multirow[t]{2}{*}{0.031} \\
\hline ever-smoker & $111(37.2 \%)$ & $28(28.6 \%)$ & $83(41.5 \%)$ & \\
\hline
\end{tabular}

Footnote: NOS, not other specified. 
Table S2 Comparison of pathological features among patients with HER2 mutations and without oncogenic mutations in patients receiving first line chemotherapy

\begin{tabular}{|c|c|c|c|c|c|c|c|}
\hline \multirow{2}{*}{ Characteristics } & \multirow{2}{*}{ total n (N\%) } & \multicolumn{3}{|c|}{ patients with HER2 mutations n (N\%) } & \multirow{2}{*}{$\begin{array}{c}\text { without oncogenic } \\
\text { mutations } \\
n(\mathrm{~N} \%)\end{array}$} & \multirow{2}{*}{$\mathrm{p}$ value $^{\dagger}$} & \multirow{2}{*}{$\mathrm{p}$ value } \\
\hline & & total & YVMA mutations & non-YVMA variants & & & \\
\hline & 132 & 82 & 55 & 27 & 50 & & \\
\hline \multicolumn{8}{|l|}{ Gender } \\
\hline male & $81(61.4)$ & $46(56.1)$ & $31(56.4)$ & $15(55.6)$ & $35(70.0)$ & 0.141 & 0.293 \\
\hline female & $51(38.6)$ & $36(43.9)$ & $24(43.6)$ & $12(44.4)$ & $15(30.0)$ & & \\
\hline \multicolumn{8}{|l|}{ Age } \\
\hline$<65$ & $91(68.9)$ & $62(75.6)$ & $42(76.4)$ & $20(74.1)$ & $29(58.0)$ & 0.052 & 0.114 \\
\hline$\geq 65$ & $41(31.1)$ & $20(24.4)$ & $13(23.6)$ & 7 (25.9) & $21(42.0)$ & & \\
\hline \multicolumn{8}{|l|}{ Histology } \\
\hline adenocarcinoma & $104(78.8)$ & $75(91.5)$ & 50 (90.9) & 25 (92.6) & $29(58.0)$ & $<0.001$ & $<0.001$ \\
\hline non-adenocarcinoma & $28(21.2)$ & $7(8.5)$ & $5(9.1)$ & $2(7.4)$ & $21(42.0)$ & & \\
\hline \multicolumn{8}{|l|}{ Smoking history } \\
\hline never-smoker & $85(64.4)$ & $58(70.7)$ & $41(74.5)$ & $17(63.0)$ & $27(54.0)$ & 0.062 & 0.084 \\
\hline ever-smoker & 47 (35.6) & $24(29.3)$ & $14(25.5)$ & $10(37.0)$ & $23(46.0)$ & & \\
\hline \multicolumn{8}{|l|}{ ECOG-PS } \\
\hline 0 & $17(12.9)$ & $13(15.9)$ & $12(21.8)$ & $1(3.7)$ & $4(8.0)$ & 0.284 & 0.026 \\
\hline $1-2$ & $115(87.1)$ & $69(84.1)$ & $43(78.2)$ & $26(96.3)$ & $46(92.0)$ & & \\
\hline \multicolumn{8}{|l|}{ Stage of disease } \\
\hline $\mathrm{IIlb} / \mathrm{Ill} \mathrm{c}$ & $15(11.4)$ & $9(11.0)$ & $6(10.9)$ & $3(11.1)$ & $6(12.0)$ & 1 & 0.931 \\
\hline IV & $107(81.1)$ & $67(81.7)$ & $46(83.6)$ & $21(77.8)$ & $40(80.0)$ & & \\
\hline recurrent & $10(7.6)$ & $6(7.3)$ & $3(5.5)$ & $3(11.1)$ & $4(8.0)$ & & \\
\hline \multicolumn{8}{|l|}{ Disease extent } \\
\hline intrathoracic & $67(50.8)$ & $43(52.4)$ & $24(43.6)$ & $19(70.4)$ & $24(48.0)$ & 0.72 & 0.067 \\
\hline extrathoracic & $65(49.2)$ & $39(47.6)$ & $31(56.4)$ & $8(29.6)$ & $26(52.0)$ & & \\
\hline \multicolumn{8}{|l|}{ Treatment regimens } \\
\hline pemetrexed based & $94(71.2)$ & $64(78.0)$ & $44(80.0)$ & $20(74.1)$ & $30(60.0)$ & 0.091 & 0.229 \\
\hline gemcitabine based & $20(22.0)$ & $14(17.1)$ & $8(14.5)$ & $6(22.2)$ & $15(30.0)$ & & \\
\hline paclitaxel based & $9(6.8)$ & $4(4.9)$ & $3(5.5)$ & $1(3.7)$ & $5(10.0)$ & & \\
\hline \multicolumn{8}{|l|}{ Responses } \\
\hline ORR & 34.1 & 37.8 & 30.9 & 51.9 & 28 & 0.264 & 0.093 \\
\hline DCR & 83.3 & 84.1 & 78.2 & 96.3 & 82 & 0.812 & 0.11 \\
\hline median PFS & 5.7 (5.14-6.19) & $5.8(5.16-6.37)$ & $5.2(4.02-6.45)$ & $7.7(5.66-9.81)$ & $5.1(3.94-6.33)$ & 0.922 & 0.109 \\
\hline
\end{tabular}

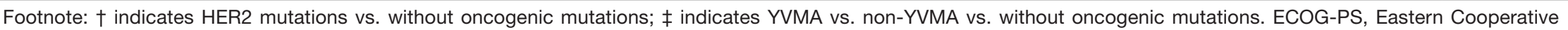
Oncology Group Performance Score; ORR, objective response rate; DCR, disease control rate; PFS, progression free survival. 
Table S3 Summary of treatment responses of patients who received first line targeted therapy

\begin{tabular}{|c|c|c|c|c|c|c|c|c|c|}
\hline Patient ID & Gender & Age & Histology & HER2 mutation & $\begin{array}{l}\text { Stage of } \\
\text { Disease }\end{array}$ & $\begin{array}{c}\text { Targeted } \\
\text { drug }\end{array}$ & $\begin{array}{c}\text { Best } \\
\text { response }\end{array}$ & $\begin{array}{c}\text { PFS } \\
\text { (months) }\end{array}$ & Living status \\
\hline 024 & female & 63.4 & adenocarcinoma & A775_G776insYVMA & $\mathrm{IVb}$ & Afatinib & SD & 5.3 & Alive \\
\hline 033 & male & 64.0 & adenocarcinoma & A775_G776insYVMA & $\mathrm{IVb}$ & Afatinib & SD & 3.3 & Alive \\
\hline 037 & female & 44.8 & adenocarcinoma & A775_G776insYVMA & $\mathrm{IVb}$ & Afatinib & SD & 6.6 & Alive \\
\hline 078 & male & 60.2 & adenocarcinoma & A775_G776insYVMA & Illb & Afatinib & PD & 2.2 & Dead \\
\hline 091 & male & 76.9 & adenocarcinoma & A775_G776insYVMA & $\mathrm{IVb}$ & Pyrotinib & PR & 19.2 & Alive \\
\hline 092 & female & 80.5 & adenocarcinoma & A775_G776insYVMA & $\mathrm{IVb}$ & Afatinib & PD & 1.9 & Dead \\
\hline
\end{tabular}

Table S4 Multivariate analysis for total patients and patients with pemetrexed based chemotherapy incorporating most prevalent baseline metastatic sites

\begin{tabular}{|c|c|c|c|c|c|c|c|c|}
\hline \multirow{3}{*}{ Variables } & \multicolumn{4}{|c|}{ Total patients $(n=82)$} & \multicolumn{4}{|c|}{ Patients received pemetrexed based chemotherapy $(n=64)$} \\
\hline & \multicolumn{2}{|c|}{ Univariate Analysis } & \multicolumn{2}{|c|}{ Multivariate Analysis } & \multicolumn{2}{|c|}{ Univariate Analysis } & \multicolumn{2}{|c|}{ Multivariate Analysis } \\
\hline & $\mathrm{HR}(95 \% \mathrm{Cl})$ & $P$ value & $\mathrm{HR}(95 \% \mathrm{Cl})$ & $P$ value & $\mathrm{HR}(95 \% \mathrm{Cl})$ & $P$ value & $\mathrm{HR}(95 \% \mathrm{Cl})$ & $P$ value \\
\hline \multicolumn{9}{|l|}{ Age, y } \\
\hline$<65$ & 1.000 & 0.330 & & & 1.000 & 0.350 & & \\
\hline$\geq 65$ & $0.757(0.432-1.326)$ & & & & $0.746(0.404-1.378)$ & & & \\
\hline \multicolumn{9}{|l|}{ Gender } \\
\hline male & 1.000 & 0.612 & & & 1.000 & 0.748 & & \\
\hline female & $1.128(0.707-1.800)$ & & & & $1.090(0.645-1.840)$ & & & \\
\hline \multicolumn{9}{|l|}{ Histology } \\
\hline adenocarcinoma & 1.000 & & & & 1.000 & & 1.000 & \\
\hline non-adenocarcinoma & $1.188(0.476-2.966)$ & 0.712 & & & $5.219(0.674-40.431)$ & 0.114 & $4.297(0.527-35.050)$ & 0.173 \\
\hline \multicolumn{9}{|l|}{ HER2 mutation } \\
\hline non-YVMA & 1.000 & 0.040 & 1.000 & 0.057 & 1.000 & 0.025 & 1.000 & 0.085 \\
\hline YVMA & $1.681(1.023-2.763)$ & & $1.633(0.985-2.706)$ & & $1.903(1.085-3.338)$ & & $1.685(0.931-3.051)$ & \\
\hline \multicolumn{9}{|l|}{ Smoking histology } \\
\hline never smoker & 1.000 & 0.328 & & & 1.000 & 0.779 & & \\
\hline ever smoker & $1.286(0.777-2.128)$ & & & & $1.089(0.600-1.976)$ & & & \\
\hline \multicolumn{9}{|l|}{ ECOG-PS } \\
\hline 0 & 1.000 & 0.770 & & & 1.000 & 0.872 & & \\
\hline $1-2$ & $0.911(0.487-1.702)$ & & & & $1.058(0.532-2.107)$ & & & \\
\hline \multicolumn{9}{|l|}{ Baseline brain metastasis } \\
\hline without & 1.000 & & & & 1.000 & & 1.000 & \\
\hline with & $1.430(0.744-2.748)$ & 0.283 & & & $2.435(1.166-5.088)$ & 0.018 & $1.900(0.845-4.273)$ & 0.121 \\
\hline \multicolumn{9}{|l|}{ Baseline bone metastasis } \\
\hline without & 1.000 & & 1.000 & & 1.000 & & 1.000 & 0.107 \\
\hline with & $1.919(1.181-3.120)$ & 0.009 & $1.788(1.072-2.981)$ & 0.026 & $1.688(0.977-2.848)$ & 0.061 & $1.601(0.903-2.837)$ & \\
\hline \multicolumn{9}{|l|}{ Baseline liver metastasis } \\
\hline without & 1.000 & & 1.000 & & 1.000 & & 1.000 & 0.370 \\
\hline with & $4.324(1.468-12.732)$ & 0.008 & $2.535(0.820-7.835)$ & 0.106 & 3.745 (1.093-12.830) & 0.036 & $1.861(0.479-7.236)$ & \\
\hline
\end{tabular}

Footnote: ECOG-PS, Eastern Cooperative Oncology Group Performance Score; HR, hazard ratio; Cl, confidential interval. 
Table S5 Detailed chemotherapy regimens used in first line and their treatment efficacy

\begin{tabular}{|c|c|c|c|c|}
\hline Regimens and Responses & total n (N\%) & YVMA n (N\%) & non-YVMA n (N\%) & \\
\hline Pemetrexed based chemotherapy & 64 & 44 & 20 & 0.735 \\
\hline pemetrexed+platinum & $53(82.8 \%)$ & $35(79.5 \%)$ & $18(90.0 \%)$ & \\
\hline pemetrexed alone & $3(4.7 \%)$ & $3(6.8 \%)$ & 0 & \\
\hline pemetrexed+platinum+bevacizumab & $8(12.5 \%)$ & $6(13.6 \%)$ & $2(10.0 \%)$ & \\
\hline \multicolumn{5}{|l|}{ Objective response } \\
\hline PR & $26(40.6 \%)$ & $14(31.8 \%)$ & $12(60.0 \%)$ & \\
\hline SD & $26(40.6 \%)$ & $19(43.2 \%)$ & $7(35.0 \% 0$ & \\
\hline PD & $12(18.8 \%)$ & $11(25.0 \%)$ & $1(5.0 \%)$ & \\
\hline ORR & $40.60 \%$ & $31.80 \%$ & $60.00 \%$ & 0.054 \\
\hline DCR & $81.30 \%$ & $75.00 \%$ & $95.00 \%$ & 0.085 \\
\hline median PFS (95\%Cl) & $5.70(5.2-6.2)$ & $5.2(3.4-7.0)$ & $6.5(2.5-10.5)$ & 0.022 \\
\hline \multicolumn{5}{|l|}{ Gemcitabine based chemotherapy } \\
\hline gemcitabine+platinum & 14 & 8 & 6 & \\
\hline \multicolumn{5}{|l|}{ Objective response } \\
\hline PR & $3(21.4 \%)$ & $2(25.0 \%)$ & $1(16.7 \%)$ & \\
\hline SD & $10(71.4 \%)$ & $5(62.5 \%)$ & $5(83.3 \%)$ & \\
\hline PD & $1(7.1 \%)$ & $1(12.5 \%)$ & 0 & \\
\hline ORR & $21.40 \%$ & $25.00 \%$ & $16.70 \%$ & 1 \\
\hline DCR & $92.90 \%$ & $87.50 \%$ & $100.00 \%$ & 1 \\
\hline median PFS (95\%Cl) & $5.2(1.9-8.6)$ & $4.2(1.7-6.7)$ & $6.6(2.5-10.8)$ & 0.635 \\
\hline \multicolumn{5}{|l|}{ Paclitaxel based chemotherapy } \\
\hline paclitaxel+platinum & 4 & 3 & 1 & \\
\hline \multicolumn{5}{|l|}{ Objective response } \\
\hline PR & $2(50.0 \%)$ & $1(33.3 \%)$ & $1(100.0 \%)$ & \\
\hline SD & $2(50.0 \%)$ & $2(66.7 \%)$ & 0 & \\
\hline PD & 0 & 0 & 0 & \\
\hline ORR & - & - & - & - \\
\hline DCR & - & - & - & \\
\hline median PFS $(95 \% \mathrm{Cl})$ & $8.2(2.2-14.1)$ & $13.87(\mathrm{NE})$ & 8.20 (NE) & 0.705 \\
\hline
\end{tabular}

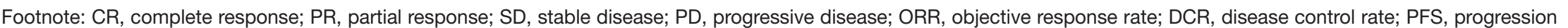
free survival; $\mathrm{Cl}$, confidential interval. 
Table S6 Summary of treatment responses of patients with baseline brain metastasis

\begin{tabular}{|c|c|c|c|c|c|c|c|c|c|c|}
\hline $\begin{array}{l}\text { Patient } \\
\text { ID }\end{array}$ & Gender & Age & Histology & HER2 mutation & $\begin{array}{l}\text { Stage of } \\
\text { Disease }\end{array}$ & $\begin{array}{l}\text { Systemic } \\
\text { Treatments }\end{array}$ & $\begin{array}{c}\text { Best } \\
\text { response }\end{array}$ & $\frac{\text { PFS }}{\text { (months) }}$ & $\begin{array}{c}\text { Local } \\
\text { treatments }\end{array}$ & $\begin{array}{l}\text { Living } \\
\text { status }\end{array}$ \\
\hline 03 & male & 43.9 & adenocarcinoma & A775_G776insYVMA & IV b & $\mathrm{GC}$ & SD & 4.2 & & Alive \\
\hline 15 & female & 66.5 & adenocarcinoma & A775_G776insYVMA & recurrent & $\mathrm{AC}$ & PD & 0.9 & & Dead \\
\hline 18 & female & 49.9 & adenocarcinoma & A775_G776insYVMA & IV b & $\mathrm{AC}$ & PR & 3.0 & & Dead \\
\hline 22 & male & 42.8 & adenocarcinoma & A775_G776insYVMA & IV b & AP+bevacizumab & PD & 1.9 & & Dead \\
\hline 24 & female & 63.4 & adenocarcinoma & A775_G776insYVMA & $\mathrm{IV} \mathrm{b}$ & Afatinib & SD & 5.3 & & Alive \\
\hline 35 & male & 67.3 & adenocarcinoma & A775_G776insYVMA & $\mathrm{IV} \mathrm{b}$ & $\mathrm{AC}+$ bevacizumab & SD & 7.8 & SRS+WBRT & Alive \\
\hline 37 & female & 44.8 & adenocarcinoma & A775_G777insYVMA & IV a & Afatinib & SD & 6.6 & Surgery & Alive \\
\hline 45 & female & 49.3 & adenocarcinoma & A775_G778insYVMA & $\mathrm{IV} \mathrm{b}$ & $\mathrm{AC}$ & PR & 8.1 & WBRT & Alive \\
\hline 50 & female & 47.2 & adenocarcinoma & A775_G779insYVMA & IV b & $\mathrm{AC}+$ bevacizumab & PR & 3.1 & & Dead \\
\hline 58 & female & 54.8 & adenocarcinoma & A775_G780insYVMA & IV a & $\mathrm{AC}$ & SD & 4.1 & & Dead \\
\hline 59 & male & 43.8 & adenocarcinoma & A775_G781insYVMA & IV b & PC & PR & 13.9 & SRS & Dead \\
\hline 62 & male & 51.1 & adenocarcinoma & A775_G782insYVMA & IV b & $\mathrm{AC}$ & PR & 5.2 & & Alive \\
\hline 64 & female & 57.2 & adenocarcinoma & A775_G783insYVMA & IV b & $\mathrm{AC}$ & SD & 2.4 & WBRT & Alive \\
\hline 90 & male & 36.0 & adenocarcinoma & A775_G784insYVMA & $\mathrm{IV} \mathrm{b}$ & GC & SD & 3.1 & WBRT+SRS & Dead \\
\hline
\end{tabular}

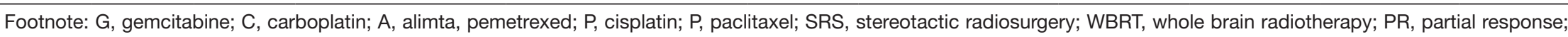
$\mathrm{SD}$, stable disease; $\mathrm{PD}$, progressive disease; ORR, objective response rate; $\mathrm{DCR}$, disease control rate; PFS, progression free survival. 